\section{Granulosis rubra nasi: a rare condition treated successfully with topical tacrolimus}

\author{
Piyush Kumar, ${ }^{1}$ Anubhav Gosai, ${ }^{2}$ \\ Ashim Kumar Mondal,2 \\ Niharika Ranjan Lal, ${ }^{2}$ \\ Ramesh Chandra Gharami ${ }^{2}$
}

${ }^{1}$ Katihar Medical College and Hospital; 2Medical College and Hospital, Kolkata, India

\section{Abstract}

A 20 years-old girl presented with multiple asymptomatic reddish vesicles on face for four years. It used to get worse in summer and was associated with localized hyperhidrosis. The lesions were notable for disappearance on diascopy. Histopathology from the vesicle showed mononuclear cell infiltration in the upper dermis, especially around eccrine sweat apparatus, along with dilatation of superficial capillaries and lymphatics. Based on clinical presentation and histopathology, diagnosis of Granulosis rubra nasi (GRN) was made. GRN usually resolves at puberty; however, rarely it may persist in adulthood. We here report a case of GRN having lesions persisting in adulthood. Moreover, she showed excellent response to topical tacrolimus, a finding not observed in literature.

\section{Introduction}

Granulosis rubra nasi (GRN) is an inflammatory condition involving eccrine sweat glands of central face and clinically presents as erythema, hyperhidrosis, papules, pustules and vesicles over central face. ${ }^{1}$ It usually presents in childhood with peak age of presentation 7-12 years. It runs a chronic course and resolves at puberty without any sequale. ${ }^{2}$ However, it may persist indefinitely. ${ }^{2}$ Here, we report a case of this rare condition, who had GRN persisting into adulthood and showed excellent response to topical Tacrolimus ointment.

\section{Case Report}

A 20 years-old girl presented with multiple discrete asymptomatic reddish vesicles over cheeks, nose, and forehead for four years (Figure 1). She had first noticed redness and increased sweating over central face 10 years back. Within 1 year, she developed multiple erythematous papules (patient stated lesions did not express fluid or whitish material on excoriation) over nose and cheeks. They used to heal without any sequale but new lesions kept appearing. There was history of summer aggravation; however, she was never lesions free, even during winter months. She had consulted various doctors and was advised many medications, including anti-acne, antibiotic, antifungal and topical steroids, with no benefit. In next 4-5 years, papular lesions stopped appearing. However, erythema over the central face was persisting. In next 1-2 years, she developed small erythematous lesions, which expressed clear and sometimes, hemorrhagic fluid on excoriation, on the central face. These lesions were persistent in nature; however, they used to increase in size on sun exposure and used to get smaller in the shade. New lesions kept appearing. Patient had noticed decreased sweating over the area, once vesicles started to appear. There were no other mucocutaneous or systemic features. On examination, multiple discrete tense vesicles on an erythematous base were present over central part of facenose, cheeks and lower part of the forehead (Figure 1). Most of these lesions were reddish in colour and expressed small amount of serosanguineous fluid. On diascopy, lesions used to disappear; however, they used to reappear after relieving the pressure. Few telangiectatic blood vessels were noted on and around the nose. Rest of the mucocutaneous and systemic examination did not reveal any abnormality. A provisional diagnosis of Granulosis rubra nasi was made, and hidrocystoma and rosacea were considered as differential diagnosis. Histopathology from the vesicle revealed mononuclear cell infiltration in the upper dermis along with dilatation of superficial capillaries and lymphatics (Figure 2A,B). Similar infiltration around sweat ducts too was noticed (Figure 2C). The findings were consistent with the diagnosis of Granulosis rubra nasi. Patient was counseled regarding the disease and poor response to treatment. A therapy with Atropine $1 \%$ cream in morning and Tacrolimus $0.03 \%$ ointment at bedtime was undertaken. On follow up after three weeks, size of the vesicles had decreased and patient stated no increase in size of the vesicles, even on sun exposure. Atropine cream was stopped fearing ocular side effects; however, Tacrolimus ointment was continued. On second follow up after another one month, patient was almost lesion free, with only few vesicles persisting (Figure 3). After having the discussion with patient, decision was made to continue Tacrolimus. After another three months of follow up, patient had not developed any new lesions and had not experienced any significant side effects of Tacrolimus. However, telangiectatic blood vessels and some erythema were still persisting.
Correspondence: Piyush Kumar, Katihar Medical College and Hospital, Kolkata, India.

E-mail: docpiyush@gmail.com

Key words: Granulosis rubra nasi, GRN, eccrine sweat glands, face, hyperhidrosis.

Received for publication: 15 July 2011.

Revision received: 2 January 2012

Accepted for publication: 3 January 2012.

This work is licensed under a Creative Commons Attribution NonCommercial 3.0 License (CC BYNC 3.0).

(C) Copyright P. Kumar et al., 2012

Licensee PAGEPress srl, Italy

Dermatology Reports 2012; 4:e5

doi:10.4081/dr.2012.e5

\section{Discussion}

GRN is an inflammatory condition involving eccrine sweat glands of nose, cheeks and chin. ${ }^{1}$ This benign condition of unknown etiology and chronic course is extremely rare and the literature is dominated by case reports only. It is widely believed that it was first described in 1901 by Jadassohn. ${ }^{1,2}$

GRN is believed to be an inherited condition. ${ }^{2,3}$ Familial cases are known and inheritance is believed to be autosomal dominant. ${ }^{2,3}$ However, etiology and pathogenesis of this disorder have not been elucidated. ${ }^{3}$ It is believed that persistent localized hyperhidrosis of central face is responsible for this condition. ${ }^{4}$ At times, hyperhidrosis of palm and sole too has been noted. ${ }^{2,3}$ Pinkus and Lebet have separately reported an association with hidrocystoma, another eccrine gland disorder. ${ }^{5,6}$ Summer aggravation of lesions is occasionally found.

It usually presents in childhood between 6 months and 15 years of age. ${ }^{7}$ Peak incidence is from age 7-12 years. ${ }^{2}$ Pinkus has described a case in man aged 59 years. ${ }^{5}$ There is no known racial or sexual predilection. ${ }^{2}$ It usually resolves spontaneously at puberty; however, it occasionally persists indefinitely. ${ }^{2}$

Excessive sweating may precede other changes by several years. It is seen over tip of nose and sometimes, cheeks. With persistent hyperhidrosis, diffuse erythema develops on nose, cheeks, and chin. This erythema may be studded with sweat droplets, giving damp glistening appearance. ${ }^{1,2}$ After this, erythematous macule, papule, or vesicle may form at sweat duct orifices., ${ }^{2,3}$ These lesions disappear on diascopy, and reappear on relieving pressure. ${ }^{1}$ The condition is largely asymptomatic; however, itching or tingling sensation may be appreciated. ${ }^{3}$ The course of the disease is extremely chronic. It usually resolves at puberty without any sequale. However, in some cases it may 
persist in adulthood. ${ }^{1,3}$ Residual telangiectasia and occasional small cysts dominate the clinical picture in such cases. ${ }^{2,8}$

The common differential diagnoses include miliaria crystallina, hidrocystoma, rosacea, periorificial dermatitis, acne vulgaris and milia.,2,3 Perioral dermatitis presents with monomorphic small papules and pustules, erythema, and scaling with a distribution primarily around the mouth. Rosacea can be differentiated by accentuation of the erythema by vasomotor instability, which is not a feature of GRN. ${ }^{7}$ Moreover, hyperhidrosis seen in GRN is not a feature of rosacea. Hidrocystoma is characterized by cystic papules of about $1-3 \mathrm{~mm}$ in diameter usually appearing in the periorbital area of middle-aged or elderly women. ${ }^{9}$ Histopathology can differentiate between these two conditions.

The diagnosis is usually made clinically. Histologically, dilation of dermal blood, and lymphatic vessels with perivascular lymphocytic infiltration and dilation of sweat ducts (at times simulating a hidrocystoma) are seen. The epidermis, connective tissue and pilosebaceous apparatus are otherwise normal and no heterotopic apocrine glands are found. ${ }^{2,3}$

No preventive measures or complications are reported and the disease has an excellent prognosis with self resolution at puberty in most cases. Hence reassurance is what is needed. ${ }^{8,10}$ Treatment with Botulinum Toxin A is under trial. ${ }^{11}$

Our case presented late with vesicular lesions. At this stage, hyperhidrosis, the characteristic feature of GRN, was absent/ minimal. The authors believe that inflammation around sweat ducts are responsible for decreased sweating and hence, vesicle formation- findings in the late stage of GRN. Owing to scarcity of literature, authors could not ascertain if other authors have had similar observation of decreased sweating in late stages. Further case reports and case series can establish/contradict our observation. Persistence of inflammation around sweat apparatus prompted us to undertake therapy with topical tacrolimus, considering poor response to topical steroids in past. We are not in a position to comment on the response of tacrolimus in earlier stages of disease process, when hyperhidrosis is prominent as we got the patient in a very late stage. We hope this case report will prompt other authors to use and document the response of tacrolimus in various stages of GRN.

\section{References}

1. Mendoza PJ, Saldana LS, Patricia AR, et al. Nasi rubra granulosis. Dermatol Peru 2003,13:125-7.

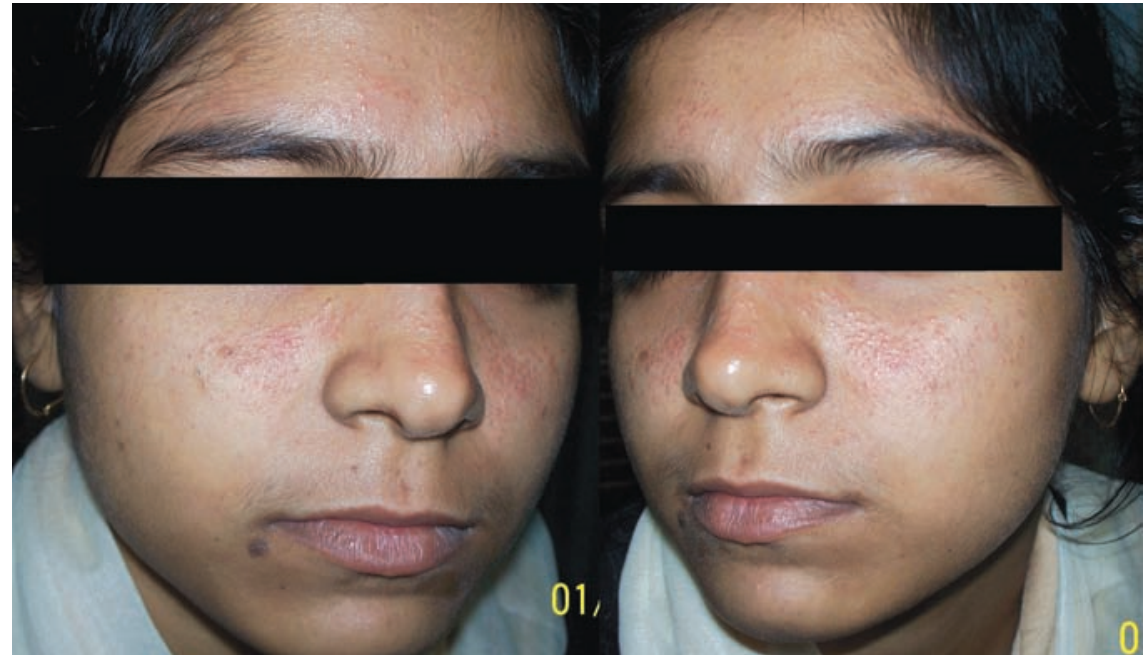

Figure 1. Discrete erythematous tense vesicles over face.

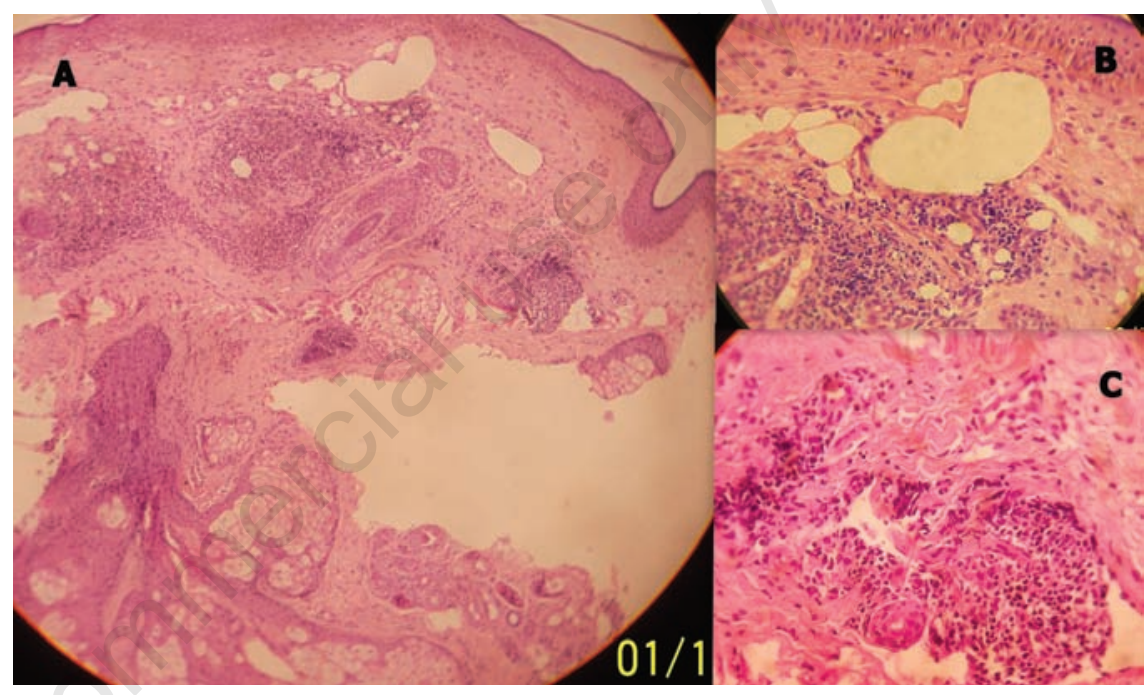

Figure 2. (A) Patchy mononuclear cell infiltration in upper dermis with dilatation of capillaries and lymphatics (Haematoxylin and Eosin stain $\times 100)$; B) patchy mononuclear cell infiltration with dilatation of capillaries and lymphatics (Haematoxylin and Eosin stain $\times 400)$; C) mononuclear cell infiltration around sweat duct (Haematoxylin and Eosin stain $\times 400$ ).

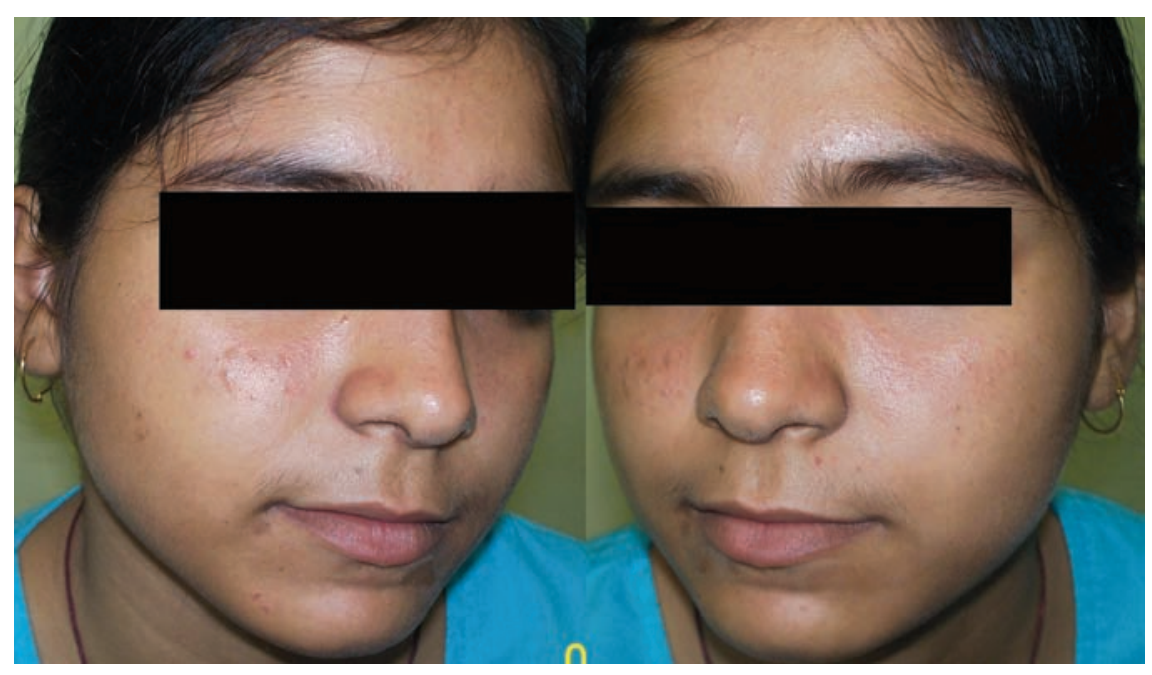

Figure 3. Successful treatment with topic. 
2. Hantash BM, Rashid RM. Granulosis rubra nasi. Avaialble from http://emedicine.medscape.com/article/1072459-overview. Accessed on March 6, 2011

3. Miller JL, Hurley HJ. Diseases of the eccrine and apocrine sweat glands. In: Bolognia JL, Jorizzo JL, Rapini RP, editors. Dermatology. 2nd edn. Philadelphia: Mosby Elsevier; 2008. pp 567-588.

4. Kreiden OP, Boni R, Burg G. Hyperhidrosis and botulinum toxic in dermatology. Curr Probi Dermato 2002;30:178-87.

5. Pinkus F. Ueber die Beziehungen des Hidrocystoms zur Granulosis rubra nasi.
Dermatologische Zeitschrift 1904;11:642-5.

6. Lebet. Constitution a l'étude de l'hidrocystome (avec une note sur la granulosis rubra nasi). Annales 1903:273.

7. Akhdari N. Granulosis rubra nasi. Int $\mathbf{J}$ Dermatol 2007:46:396.

8. Coulson IH. Disorders of sweat glands. In: Burns T, Breathnach S, Cox N, Griffiths C (eds). Rook's textbook of dermatology. 8th edition. West Sussex: Wiley Blackwell Publishers; 2010. pp 44-18.

9. Ghosh SK, Bandyopadhyay D, Biswas SK, Mandal RK. Multiple translucent papules on the face of a middle-aged woman.
Indian J Dermatol Venereol Leprol 2010; 76:721-2.

10. James WD, Berger TG, Elston DM . Diseases of the skin appandages. In: James WD, Berger TG, Elston DM (eds). Andrew's Disease of the Skin. 10th edition. Canada: Saunders Elsevier publications; 2009. p 780 .

11. Grazziotin TC, Buffon RB, da Silva Manzoni AP, et al. Treatment of granulosis rubra nasi with botulinum toxin type A. Dermatol Surg 2009;35:1298-9. 